\title{
On the Dynamics of Mechanical Structures Under Non-ideal Excitations
}

\author{
Nanha Djanan $\mathrm{AA}^{*}$ and Nana Nbendjo BR \\ Laboratory of Modelling and Simulation in Engineering, Biomimetics and Prototypes, University of Yaoundé I, Cameroon
}

Submission: June 06, 2018; Published: September 04, 2018

*Corresponding author: Nanha Djanan AA, Laboratory of Modelling and Simulation in Engineering, Biomimetics and Prototypes, University of Yaoundé I, Cameroon; Tel: 2.37699E+11; Email: nandjaor@yahoo.fr

\section{Abstract}

The present paper briefly describes the dynamics behavior of mechanical structures when they are subjected to a non-ideal energy power supply source. Different approaches which can be used to reduce the amplitude of vibration in the structure are described. Main results obtained during dynamic's explanation shows that by adjusting the non-ideal sources one can influence positively the response of the physical system.

Keywords: DC motor; Non-ideal sources; Dynamics; Vibrations

\section{Introduction}

The study of dynamic response of mechanical structures is interesting and important, as some of the results may be applicable in understanding the dynamic behavior of structure and buildings. Several engineering structures such as buildings, airplanes wings, helicopter blades, bridges are usually subjected to various types of vibrations. These vibrations may result from wind gusts, high speeding cars, rotating machines and some environmental disturbances. The dynamic response of mechanical and civil structures prone to high-amplitude motions is often undesirable and dangerous. Frequently, we encounter in civil engineering situation where an elastic structure is excited by a DC motor leading to high amplitude of vibration.

The vibrations of linear dynamical systems have been studied exhaustively over the last years and significant

\section{General Formalism}

contributions have been also made to the theory of vibrations of non-linear dynamical systems. The problem of passage through resonance of dynamical systems has obtained special attention of the engineering researchers in the last years but unfortunately have few literatures on this subject related to non-ideal vibrating problems. In 1889, Laval was the first one who recognized the problem of interaction between the energy source and working machine during the passage through resonance [1]. However, when the excitation of a vibrating system is not influenced by its response, it is said to be an ideal excitation or an ideal source of energy. On the other hand, when the excitation is influenced by the response of the system, it is said to be non-ideal one. The following section consists to the presentation of the general formalism of ideal system, section 5 is devoted to the main results and section 6 to the conclusion.

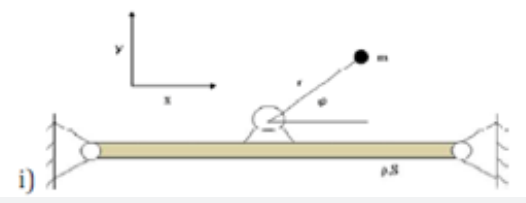

ii)

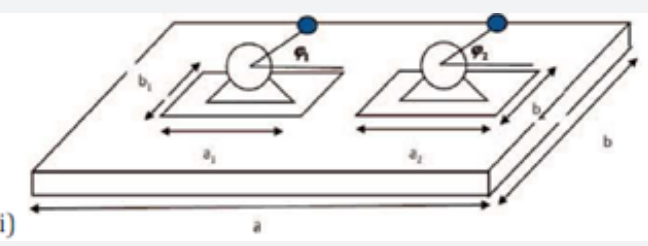

Figure 1: Sample of a nonideal systems encountered in civil engineering: i) a hinged-hinged beam supporting a DC motor with limited power supply ii) rectangular plate supporting two DC motors moving in the same direction.

The behavior of ideal vibrating systems is well known in the current literature, but there are few results on non-ideal ones. Contrary to their counterpart, non-ideal vibrating systems have one more degree of freedom [1]. It is also known for nonideal systems that sometimes the passage through resonance requires more input power than the dynamical system driven has available. Figure 1 shows two examples of non-ideal system. Through some well-known mathematical approaches (Lagrange, Hamilton principle,...) we can built the general form of dynamical equations of a non-ideal as follow [2-6]: 


$$
\left\{\begin{array}{l}
\text { Dynamic Equation of the supporting structure = Interaction terms } \\
J \frac{d^{2} \varphi}{d t^{2}}+F\left(\frac{d \varphi}{d t}\right)=\text { Other Interaction terms }
\end{array}\right.
$$

Some studies have proven that one can used some electric transducers [2,3] connected to the main structure to come through the amplitude of vibration in the mechanical structure. Thus, we obtained the following system:

$$
\left\{\begin{array}{l}
\text { Dynamic equation of the structure }=\text { Interactions terms }+ \text { Coupling terms } \\
J \frac{d^{2} \varphi}{d t}+L\left(\frac{d \varphi}{d t}\right)=\text { Other Interaction terms } \\
\text { Dynamic equation of the controller }=\text { Another Coupling terms }
\end{array}\right.
$$

More recently, it has been shown [4-6] that when two or more non-ideal sources are resting or moving on a rectangular plate it is possible to get a new dynamic in the system. This is obtained through the following system where i refer to the number of non-ideal sources:

$$
\left\{\begin{array}{l}
\text { Dynamic equation of the structure }=\text { Interactions terms (equal to the number of DC sources } \\
J i \frac{d^{2} \varphi^{i}}{d t}+L i\left(\frac{d \varphi^{i}}{d t}\right)=\text { Other Interaction terms }
\end{array}\right.
$$

The exploration of these previous equations through analytical and numerical methods leads to a large number of results, but only the principals will be present in the next section.

\section{Main Results}

Comparison between analytical and numerical results obtained when we used transducers as controller of lead us to appreciate a great concordance [2,3]. Thus, it is therefore possible to predict the effects of some physical parameters of the system (structure or controller) on the reduction of vibration amplitude in the structure. It is also possible analytically to obtain the condition for the effectiveness of the control strategy [2]. Moreover, to enhance the control strategy it is quite possible to select the good parameters to get the stability of the system when it is controlled.

In a situation where two or more non-ideal sources are resting on a mechanical structure, it is possible to show through numerical simulation, the effect of the main frequency structure on the self-synchronization which appears between the non-ideal sources [4]. Thus, it is observed that amplitudes of vibration are less in the structure for anti-phase synchronization between the sources. However, in the case of more DC motors resting on the structure, we denote that the way of rotating in different direction is crucial for the reduction of amplitude in the structure [5]. The phase difference too between sources is also quite important for the reduction of amplitude in the system.

For two DC motors with limited power supply moving on a plate, we denote the impact of the way of crossing of the motorson the plate amplitude, and it is showed that the physical characteristics of the motors contribute to the reduction in the plate vibration [6]. The analytical approach used leads to some mathematical expressions, which leads us to some predictions on vibration amplitude in the system. According to analytical analysis, to avoid high amplitude of vibration, it is desirable to well master the angular velocity of the DC motors, the unbalanced masses, the excentricity, the plate density and his dimensions.

\section{Conclusion}

In this review, the problem of dynamics and vibration control of mechanical structure submitted to the vibrations of rotating machines with limited power supply is treated. Such systems are usually called non-ideal systems. The first section devoted to the literature review presents a large number of applications of mechanical structures under various type of excitation, then follows by some information about DC motor with limited power supply. The general formalism of the vibration control of rectangular plate is presented in two steps. The first one concerns the used of electric transducer as controller device and the second the synchronization phenomenon appearing between the external excitation.

The recent results on the subject shows that the implementation of the control strategy leads to obtain the condition for which the control is effective, the effect of some control parameters on the reduction of the amplitude are displayed and the stability condition of all the system is established in order to enhance the efficiency of the control strategy used. The main phenomenon observes is the selfsynchronization appearing between the DC sources with time. This really affects the amplitude of vibration of the structure through his physicals characteristics.

\section{References}

1. Balthazar JM, Mook DT, Weber HI, Brasil RMLRF, Fenili A, et al. (2003) An overview on nonideal vibrations. Meccanica 38(6): 613-621.

2. Nanha Djanan AA, Nana Nbendjo BR, Woafo P (2011) Control of vibration on a hinged-hingedbeam under a non-ideal excitation using RLC circuit with variable capacitance. Nonlinear Dynamics 63: 477489.

3. Nanha Djanan AA, Nana Nbendjo BR, Woafo P (2013) Electromechanical control of vibration on a plate submitted to a non-ideal excitation. Mechanics Research Communication 54: 72-82.

4. Nanha Djanan AA, Nana Nbendjo BR, Woafo P (2015) Selfsynchronization of two motorson a rectangular plate and reduction of vibration. Journal of Vibration and Control 21(11): 2114-2123.

5. Nanha Djanan AA, Nana Nbendjo BR, Woafo P (2014) Effect of selfsynchronization of DC motors on the amplitude of vibration of a rectangular plate. The European Physics Journal ST 223(4): 813-825.

6. Nanha Djanan AA, Nana Nbendjo BR (2018) Effect of two moving non-ideal sources on the dynamic of a rectangular plate. Nonlinear Dynamics 92(2): 645-657. 
Your next submission with Juniper Publishers will reach you the below assets

- Quality Editorial service

- Swift Peer Review

- Reprints availability

- E-prints Service

- Manuscript Podcast for convenient understanding

- Global attainment for your research

- Manuscript accessibility in different formats ( Pdf, E-pub, Full Text, Audio)

- Unceasing customer service

Track the below URL for one-step submission https://juniperpublishers.com/online-submission.php 